Omrani, H., S. Mohammadi,A. Emrouznejad (2018). A bi-level multi-objective data envelopment analysis model for estimating profit and operational efficiency of bank branches. RAIRO Operations Research, Accepted.

\title{
A bi-level multi-objective data envelopment analysis model for estimating profit and operational efficiency of bank branches
}

\author{
Hashem Omrani ${ }^{1 *}$, Setareh Mohammadi ${ }^{1}$ and Ali Emrouznejad ${ }^{2}$ \\ ${ }^{1}$ Faculty of Industrial Engineering, Urmia University of Technology, Urmia, Iran \\ ${ }^{2}$ Aston Business School, Aston University, Birmingham, UK
}

\begin{abstract}
Data Envelopment Analysis (DEA) is a powerful method for analyzing the performance of decision making units (DMUs). Traditionally, DEA is applied for estimating the performance of a set of $\mathrm{DMU}_{\mathrm{s}}$ through measuring a single perspective of efficiency. However, in recent years, due to increasing competition in various industries, modern enterprises focus on enhancing their performance by measuring efficiencies in different aspects, separately or simultaneously. This paper proposes a bi-level multi-objective DEA (BLMO DEA) model which is able to assess the performance of DMUs in two different hierarchical dimensions, simultaneously. In the proposed model, we define two level efficiency scores for each DMU. The aim is to maximize these two efficiencies, simultaneously, for each DMU. Since the objective functions at both levels are fractional, a fuzzy fractional goal programming (FGP) methodology is used to solve the proposed BLMO DEA model. The capability of the proposed model is illustrated by a numerical example. Finally, to practically validate the proposed model, a real case study from 45 bank's branches is applied. The results show that the proposed model can provide a more comprehensive measure for efficiency of each bank's branch based on simultaneous measuring of two different efficiencies, profit and operational efficiencies, and by considering the level of their importance.
\end{abstract}

Keywords: Data Envelopment Analysis (DEA), Bi-level programming, Fuzzy programming, Bank efficiency

\section{Introduction}

Banks, as an essential component in leading and directing the capitals to the production units, plays a fundamental role in the economic growth of the countries. In general, any activity that requires capital and financial resources

${ }^{* 1}$ Corresponding Author, Tel: +984433554180, Fax: +98-4413554181, Email address: $\underline{\text { h.omrani@uut.ac.ir }}$ 
needs to be processed by banks and financial institutions. Top bank managements have a duty to enhance banks productivity to achieve satisfactory results while they must identify inefficient branches and remove the causes of inefficiencies. Performance analysis of branches is a very complicated process. Hence, the concept of performance analysis in banking industry has become one of the most important issues. There are different approaches for evaluating bank branches. Some of performance evaluation methods are included ratio analysis, regression analysis, analytic hierarchy process (AHP), TOPSIS, balanced scorecard (BSC) and etc (Paradi and Zhu, 2012). Among all of the techniques for bank performance analysis, data envelopment analysis (DEA) is the most frequent method which was proposed by Charnes et al. (1978). Duygun Fethi and Pasiouras (2010) showed that among 196 papers in the period 1998 to 2009, 151 studies applied DEA for estimating efficiency of bank and branches.

In the bank branch assessment literature, some studies have focused on a single perspective of efficiency. Sherman and Gold (1985) presented the first DEA application to generate efficiency measurement for 14 branches of an US bank. Parkan (1987) presented an application of DEA with 13 inputs and 18 outputs to find out the operational efficiency of bank branches. Yang (2009) suggested a DEA model to evaluate operational efficiency of 240 branches of big Canadian bank in Toronto. Ray (2016) evaluated overall cost efficiency of a number of Indian bank branches using DEA approach in order to find the optimal number of branches.

Jahanshahloo et al. (2004) noted that in many real situations, the system under evaluation is considered as a multifunction unit means which can be separated into different efficiency measurement components. In fact, evaluation in a single perspective of efficiency cannot reflect the performance of a bank. There are only a few studies that have analyzed bank performance in different perspectives. Some of them focused on simultaneous analysis of multiple efficiencies. In these situations, input variables are often common between efficiency measures and outputs are different for the efficiencies. Cook and Hababou (2001) developed a goal programming version of additive DEA to evaluate the sales and service efficiencies of the bank branches, simultaneously. In this study, they include common inputs while using different outputs for each efficiency. Paradi et al. (2010) developed a two-stage DEA model for evaluating Canadian bank branches. First, they applied three DEA model for production, profit and intermediation efficiencies, then, the three efficiency scores are embedded into a single value to produce a composite measure of performance for each branch. Ariff and Can (2008) measured the cost and profit efficiency of 28 Chinese commercial banks by using DEA. They found that joint-stock banks, on average, were more cost and profit efficient than state-owned banks. Arjomandi et al. (2014) investigated how the performance of banking sector in Iran has 
been affected by the policy reforms. They evaluated both intermediation and operational performance by a DEAbased decomposition of the Hicks-Moorsteen TFP index. They also showed that under the intermediation approach, public banks were more efficient than private banks in the post-regulation period while private banks were fully efficient under the operating approach. Giokas (2008) used DEA model to assess the performance of individual branches of a Greek bank in three different dimensions: production efficiency for managing the economic record, transaction efficiency for meeting customer transaction demands, and profit efficiency for generating profits. Also, he found a correlation between transaction-production, profitability-production and profitability-transaction efficiencies.

Literature has also reported a number of studies that have measured profit and operational efficiencies to evaluate bank performance (Emrouznejad and Yang, 2018). Oral et al. (1992) investigated a link between operating efficiency and profitability efficiency by using the correlation between DEA efficiency scores. Portela and Thanassoulis (2005) explained changing the role of bank branches from a transaction-based to a sales-oriented role. Hence, selecting suitable efficiency measures which consider sales activities and profit of branches can help mangers to increase sale, customers and profit of branches. In a similar study, Portela and Thanassoulis (2007) developed a DEA model to identify benchmark for problematic branches by focusing on three dimensions of performance: transactional, operational and profit to assess the branches of a Portuguese bank. They Also, they found positive links between operational-profit, transactional-operational, service quality-operational and service quality-profit efficiencies. Paradi and Zhu (2012) explained various measures for surveying branches efficiency. Manandhar and Tang (2001) proposed simultaneous benchmarking of the performance of bank branches along three dimensions: internal service quality, operating efficiency and profitability using a modified DEA model. Oral and Yolalan (1990) discussed a method based on DEA to measure the operation and profit efficiencies of 20 branches of a Turkish bank. Their results showed that there was a relationship between operation and profit efficiency and those branches which are most efficient in service are also the most profitable ones. Ghasemi et al (2014) provided a biobjective weighted model for improving the discrimination power in Multi Criteria DEA models.

As reviewed above, previous studies utilized various forms of DEA to analyze bank performance by measuring either a single or different kinds of efficiency, separately. However, there is no study which addresses a simultaneous evaluation of efficiency for bank branches from different aspects. Motivated by this challenging gap, in this paper, a novel bi-level multi-objective DEA model is introduced to simultaneously assess a set of 
homogenous $\mathrm{DMU}_{\mathrm{s}}$ including bank branches in two different dimensions. The advantage of the proposed model is that, due to its bi-level structure, it establishes a hierarchical relationship between two different measures which is suitable whenever one of these efficiencies has a more significant effect on improving organizations' performance. To practically validate the proposed model, we have applied a case study from a big Iranian bank, where due to the vital role of revenue for Iran's banks, profit efficiency is assigned to the first level and operational efficiency with less importance is considered at the second level. Mathematically, the model is a fractional programming model which is solved by utilizing the fuzzy goal programming (FGP) approach proposed by Lachhwani (2015). For information on fuzzy DEA models see Emrouznejad et al (2014) and Wanke et al (2017).

The organization of the paper is as follow: Section 2 describes the proposed model and it's solving steps. A numerical example is given in section 3 to illustrate the capability of the proposed model. Section 4 introduces the inputs and outputs and actual data from 45 branches of Maskan bank in Iran. Section 5 discusses the results and provides a comparative study with the standard DEA model. Finally, the conclusion and direction for future research are discussed in section 6.

\section{Methodology}

This section first presents a brief review of the traditional DEA-CCR model, then introduces the proposed bi-level multi-objective DEA model, and finally illustrates the solution procedure in detail.

\subsection{DEA-CCR model}

Let assume there are $n D M U$ which will be evaluated by $m$ different inputs and $s$ different outputs. Each $D M U$ produce the amounts $y_{j}=\left\{y_{r j}\right\}$ of outputs $(r=1, \ldots, s)$ by using the amounts $x_{j}=\left\{x_{i j}\right\}$ of inputs $(i=1, \ldots, m)$. It's also assumed that the input $x_{i j}$ and output $y_{r j}$ are nonnegative. The efficiency of $D M U_{j}$ can be calculated as:

$\theta_{j}=\frac{\sum_{r=1}^{s} u_{r} y_{r j}}{\sum_{i=1}^{m} v_{i} x_{i j}} \quad j=1, \ldots, \mathrm{n}$

where $u_{r}$ and $v_{i}$ are the outputs and inputs weights, respectively. As introduced by Charnes et al. (1978), the following linear DEA-CCR model measures the efficiency of each DMU in which the objective function of the model is a weighted sum of outputs. 


\section{Model (1): Classical DEA-CCR model}

$\max \theta_{0}=\sum_{r=1}^{s} u_{r} y_{r o}$

Subject to:

$$
\begin{aligned}
& \sum_{r=1}^{s} u_{r} y_{r j}-\sum_{i=1}^{m} v_{i} x_{i j} \leq 0 \quad j=1, \ldots, n \\
& \sum_{i=1}^{m} v_{i} x_{i o}=1 \\
& u_{r}, v_{i} \geq \varepsilon \quad r=1, \ldots, s ; i=1, \ldots, m
\end{aligned}
$$

where $o$ is the DMU under evaluation and $\varepsilon$ is a non negative arbitrary infinitesimal value to prevent assigning a zero value to the weights. If $\theta_{0}=1$ and all slacks are zero, then the DMU $o$ is considered as an efficient unit.

\subsection{Proposed BLMO DEA model}

This study introduces a novel bi-level multi-objective DEA (BLMO DEA) model to measure two different hierarchical dimension efficiencies for a set of homogeneous DMUs. More specifically, the proposed model provides a suitable performance assessment system based on simultaneous evaluating of two different aspects of efficiencies with different levels of importance in performance of the organizations. Technically, this model is based on the combination of the DEA-CCR and bi-level programming in which two different types of efficiencies are formulated in a bi-level multi-objective DEA framework. In the proposed framework, the first important efficiency is considered at level 1 and the second important one is assigned to the level 2, where the model tries to simultaneously maximize both efficiencies of all units by considering the hierarchical relationship between them.

Let assume that there are $n$ DMUs which management wants to evaluate all units through measuring two different efficiencies, each of efficiencies has a unique impact on the organizations' performance. Since the classical DEACCR model is not capable to estimate the efficiencies of such cases, this study extends it to a multi-objective structure with $n$ separate efficiency function in order to assess the performance of all DMUs. Besides, to cope with the challenge of the evaluation of different levels, the bi-level framework is applied, where the first important 
efficiency of all DMUs is maximized by considering the optimization of the second important one. In the following the proposed BLBO DEA model is presented.

\section{Model (2): BLMO DEA model}

level $1=\max \left\{\frac{\sum_{r=1}^{s} u_{r}^{(1)} y_{r 1}^{(1)}}{\sum_{i=1}^{m} v_{i}^{(1)} x_{i 1}^{(1)}}, \frac{\sum_{r=1}^{s} u_{r}^{(1)} y_{r 2}^{(1)}}{\sum_{i=1}^{m} v_{i}^{(1)} x_{i 2}^{(1)}}, \ldots, \frac{\sum_{r=1}^{s} u_{r}^{(1)} y_{r n}^{(1)}}{\sum_{i=1}^{m} v_{i}^{(1)} x_{i n}^{(1)}}\right\}$

level $2=\max \left\{\frac{\sum_{r=1}^{s} u_{r}^{(2)} y_{r 1}^{(2)}}{\sum_{i=1}^{m} v_{i}^{(2)} x_{i 1}^{(2)}}, \frac{\sum_{r=1}^{s} u_{r}^{(2)} y_{r 2}^{(2)}}{\sum_{i=1}^{m} v_{i}^{(2)} x_{i 2}^{(2)}}, \ldots, \frac{\sum_{r=1}^{s} u_{r}^{(2)} y_{r n}^{(2)}}{\sum_{i=1}^{m} v_{i}^{(2)} x_{i n}^{(2)}}\right\}$

Subject to:

$$
\begin{array}{ll}
\sum_{r=1}^{s} u_{r}^{(l)} y_{r j}^{(l)}-\sum_{i=1}^{m} v_{i}^{(l)} x_{i j}^{(l)} \leq 0 & j=1,2, \ldots, n ; l=1,2 \\
\sum_{r=1}^{s} u_{r}^{(l)}+\sum_{i=1}^{m} v_{i}^{(l)}=1 & l=1,2 \\
u_{r}^{(l)}, v_{i}^{(l)} \geq \varepsilon & r=1,2, \ldots, \mathrm{s} ; i=1,2, \ldots, \mathrm{m} ; l=1,2
\end{array}
$$

where $l=1,2$ is the number of levels or efficiencies and $j=1,2, \ldots, n$ is the number of branches. Also, $r=1,2, \ldots, s$ and $i=1,2, \ldots, m$ denote the number of outputs and the number of inputs, respectively. $u_{r}^{(l)}$ and $v_{i}^{(l)}$ are the weights of output $r$ th and input $i$ th at level $l$, respectively. The value of input $i$ th for branch $j$ th at level $l$ is represented as $x_{i j}^{(l)}$. In addition, the value of output $r$ th for branch $j$ th at level $l$ is represented as $y_{r j}^{(l)}$. In the proposed framework, constraints (8) and (10) are the DEA-CCR model constraints. Besides, constraint (9) is added to normalize the weights and prevent unbounded solution.

In order to solve the proposed model (2) with fractional objective functions, a fuzzy goal programming (FGP) methodology is applied which is very common method for solving multi-level multi-objective linear fractional programming problems (Lachhwani, 2015). To formulate FGP methodology for model (2), the numerator objective function $f\left(Y_{j}^{(l)}\right) j=1,2 \ldots, n ; l=1,2$, denominator objective function $f\left(X_{j}^{(l)}\right) j=1,2 \ldots, n ; l=1,2$, and the 
weights $u_{r}^{(l)}$ and $v_{i}^{(l)} r=1,2, \ldots, \mathrm{s} ; \mathrm{i}=1,2, \ldots, \mathrm{m} ; l=1,2$ should be changed into fuzzy goals. Then, the membership function of $j^{(l)}$ th numerator objective function, denominator objective function and weights would be determined by defining an aspired level for each of them. The linear membership functions for numerator and denominator objective functions of $j$ th branch at level $t$ are as follows, respectively:

$\mu\left(Y_{j}^{(l)}\right)= \begin{cases}1 & \text { if } Y_{j}^{(l)} \geq \bar{Y}_{j}^{(l)} \\ \frac{Y_{j}^{(l)}-\bar{Y}_{j}^{(l)}}{\bar{Y}_{j}^{(l)}-\underline{Y}_{j}^{(l)}} & \text { if } \underline{Y}_{j}^{(l)} \leq Y_{j}^{(l)} \leq \bar{Y}_{j}^{(l)} \quad j=1,2, \ldots, \mathrm{n} ; l=1,2 \\ 0 & \text { if } Y_{j}^{(l)} \leq \underline{Y}_{j}^{(l)}\end{cases}$

$$
\mu\left(Y_{j}^{(l)}\right)= \begin{cases}1 & \text { if } Y_{j}^{(l)} \geq \bar{Y}_{j}^{(l)} \\ \frac{Y_{j}^{(l)}-\bar{Y}_{j}^{(l)}}{\bar{Y}_{j}^{(l)}-\underline{Y}_{j}^{(l)}} & \text { if } \underline{Y}_{j}^{(l)} \leq Y_{j}^{(l)} \leq \bar{Y}_{j}^{(l)} \quad j=1,2, \ldots, \mathrm{n} ; l=1,2 \\ 0 & \text { if } Y_{j}^{(l)} \leq \underline{Y}_{j}^{(l)}\end{cases}
$$

where $\bar{Y}_{j}^{(l)}$ and $\overline{\mathrm{X}}_{j}^{(l)}$ are upper limits or the maximum values for each objective function. Similarly, $\underline{Y}_{j}^{(l)}$ and $\underline{\mathrm{X}}_{j}^{(l)}$ are lower limits or the minimum values of each row for each objective function. Also, linear membership functions of $u_{r}^{(l)}$ and $v_{i}^{(l)}$ are formulated as (13) and (14), respectively:

$$
\begin{aligned}
& \mu\left(u_{r}^{(l)}\right)= \begin{cases}1 & \text { if } u_{r}^{(l)} \geq \bar{u}_{r}^{(l)} \\
\frac{u_{r}^{(l)}-\underline{u}_{r}^{(l)}}{\bar{u}_{r}^{(l)}-\underline{u}_{r}^{(l)}} & \text { if } \underline{u}_{r}^{(l)} \leq u_{r}^{(l)} \leq \bar{u}_{r}^{(l)}, r=1,2, \ldots, s ; l=1,2 \\
0 & \text { if } \bar{u}_{r}^{(l)} \leq \underline{u}_{r}^{(l)}\end{cases} \\
& \mu\left(v_{i}^{(l)}\right)= \begin{cases}1 & \text { if } v_{i}^{(l)} \geq \bar{v}_{i}^{(l)} \\
\frac{v_{i}^{(l)}-\underline{v}_{i}^{(l)}}{\bar{v}_{i}^{(l)}-\underline{v}_{i}^{(l)}} & \text { if } \underline{v}_{i}^{(l)} \leq v_{i}^{(l)} \leq \bar{v}_{i}^{(l)}, i=1,2, \ldots, m ; l=1,2 \\
0 & \text { if } \bar{v}_{i}^{(l)} \leq \underline{v}_{i}^{(l)}\end{cases}
\end{aligned}
$$


where $\bar{u}_{r}^{(l)}$ and $\bar{v}_{i}^{(l)}$ are the maximum values of $u_{r}^{(l)}$ and $v_{i}^{(l)}$, respectively. For achieving highest degree of each membership function, all of them are provided in a single model by minimizing their negative deviational variables. So, the single model which contains membership goals is as follow:

$\mu\left(Y_{j}^{(l)}\right)+d_{j}^{Y_{-}^{(l)}}-d_{j}^{y_{+}^{(l)}}=1 \quad \forall j=1,2, \ldots, n ; l=1,2$

$\mu\left(X_{j}^{(l)}\right)+d_{j}^{X_{-}^{(l)}}-d_{j}^{X_{+}^{(l)}}=1 \quad \forall j=1,2, \ldots, n ; l=1,2$

$\mu\left(u_{r}^{(l)}\right)+d_{u_{r}^{(l)}}^{-}-d_{u_{r}^{(l)}}^{+}=1 \quad \forall r=1,2, \ldots, \mathrm{m} ; l=1,2$

$\mu\left(v_{i}^{(l)}\right)+d_{v_{i}^{(l)}}^{-}-d_{v_{i}^{(l)}}^{+}=1 \quad \forall i=1,2, \ldots, \mathrm{s} ; l=1,2$

where $d_{j}^{y_{+}^{(l)}}, d_{j}^{X_{+}^{(l)}}, d_{j}^{y_{-}^{(l)}}, d_{j}^{X_{-}^{(l)}}(\geq 0)(j=1,2, \ldots, n ; l=1,2)$ are positive and negative deviation variables, respectively. Similarly, $d_{u_{r}^{(l)}}^{+}, d_{v_{i}^{(l)}}^{+}, d_{u_{r}^{(l)}}^{-}, d_{v_{i}^{(l)}}^{-}(\geq 0)\left(\forall_{r}=1,2, \ldots, s ; i=1,2, \ldots, \mathrm{m} ; l=1,2\right) \quad$ are $\quad$ positive $\quad$ and negative deviation variables, respectively. As mentioned above, for achieving highest degree of membership goals, the negative deviation variables would be minimized. Finally, the proposed BLMO DEA model (2) is changed to the following fuzzy goal programming (FGP) model (3):

\section{Model (3): A fuzzy goal programming for solving BLMO DEA problem}

$$
\min \lambda=\sum_{j=1}^{n} \sum_{t=1}^{2} d_{j}^{y_{-}^{(l)}}+\sum_{j=1}^{n} \sum_{t=1}^{2} d_{j}^{X_{-}^{(l)}}+\sum_{r=1}^{s} \sum_{t=1}^{2} d_{u_{r}^{(l)}}^{-}+\sum_{i=1}^{m} \sum_{t=1}^{2} d_{v_{i}^{(l)}}^{-}
$$

Subject to:

$$
\begin{array}{ll}
-\bar{Y}_{j}^{(l)}+Y_{j}^{(l)}+d_{j}^{Y_{-}^{(l)}}\left(\bar{Y}_{j}^{(l)}-\underline{Y}_{j}^{(l)}\right) \geq 0 & \forall_{j}=1,2, \ldots, n ; l=1,2 \\
\underline{X}_{j}^{(l)}-X_{j}^{(l)}+d_{j}^{X_{-}^{(l)}}\left(\bar{X}_{j}^{(l)}-\underline{X}_{j}^{(l)}\right) \geq 0 & \forall_{j}=1,2, \ldots, n ; l=1,2 \\
-\bar{u}_{r}^{(l)}+u_{r}^{(l)}+d_{u_{r}^{(l)}}^{-}\left(\bar{u}_{r}^{(l)}-\underline{u}_{r}^{(l)}\right) \geq 0 & \forall_{r}=1,2, \ldots, s ; l=1,2 \\
-\bar{v}_{i}^{(l)}+v_{i}^{(l)}+d_{v_{i}^{-}(l)}\left(\bar{v}_{r}^{(l)}-\underline{v}_{i}^{(l)}\right) \geq 0 & \forall_{i}=1,2, \ldots, \mathrm{m} ; l=1,2
\end{array}
$$




$$
\begin{array}{ll}
\sum_{r=1}^{s} u_{r}^{(l)} y_{r j}^{(l)}-\sum_{i=1}^{m} v_{i}^{(l)} x_{i j}^{(l)} \leq 0 & \forall_{j}=1,2, \ldots, n ; l=1,2 \\
\sum_{r=1}^{s} u_{r}^{(l)}+\sum_{i=1}^{m} v_{i}^{(l)}=1 & \forall_{l}=1,2 \\
u_{r}^{(l)}, v_{i}^{(l)} \geq \varepsilon & \forall_{r}=1,2, \ldots, \mathrm{s} ; i=1,2, \ldots, \mathrm{m} ; l=1,2
\end{array}
$$

where $\lambda$ represents the degree achievement of fuzzy functions by minimizing negative deviational variables.

\section{An illustrative example}

This section presents an illustrative example to show the applicability of the proposed model. Assume there are five DMUs which manger wants to evaluate them through measuring the profit and operational efficiencies. Profit efficiency focuses on the assessment of the DMUs' ability on generating revenue, while, operational efficiency deals with measuring any kinds of operations that carried out in a DMU. From the view point of the manager, profitability is very important in the DMUs' evaluation. So, a challenging issue faced by the management is that how should evaluate DMUs in two different aspects by considering the differentiation between the levels of the efficiencies. Table (1) presents the data for inputs and outputs of the two levels profit (level 1) and operational (level 2) efficiencies, respectively.

\section{------- [Table 1 about here] -------}

It is assumed that there are three output variables $y_{1}, y_{2}$ and $y_{3}$ for calculating profit efficiency and two outputs $y_{1}^{\prime}, y_{2}^{\prime}$ for estimating operational efficiency. The inputs $x_{1}, x_{2}$ and $x_{3}$ are considered as common variables between the two levels. Therefore, according to proposed model (2), we have:

$$
\begin{aligned}
& \text { level } 1=\max \left(\frac{4 u_{1}+3 u_{2}+2 u_{3}}{7 v_{1}+7 v_{2}+7 v_{3}}, \frac{7 u_{1}+5 u_{2}+u_{3}}{5 v_{1}+9 v_{2}+7 v_{3}}, \frac{7 u_{1}+u_{2}+7 u_{3}}{4 v_{1}+6 v_{2}+5 v_{3}}, \frac{2 u_{1}+u_{2}+3 u_{3}}{5 v_{1}+9 v_{2}+8 v_{3}}, \frac{6 u_{1}+2 u_{2}+4 u_{3}}{6 v_{1}+8 v_{2}+5 v_{3}}\right) \\
& \text { level } 2=\max \left(\frac{4 u_{1}^{\prime}+3 u_{2}^{\prime}}{7 v_{1}+7 v_{2}+7 v_{3}}, \frac{7 u_{1}^{\prime}+5 u_{2}^{\prime}}{5 v_{1}+9 v_{2}+7 v_{3}}, \frac{5 u_{1}^{\prime}+u_{2}^{\prime}}{4 v_{1}+6 v_{2}+5 v_{3}}, \frac{6 u_{1}^{\prime}+u_{2}^{\prime}}{5 v_{1}+9 v_{2}+8 v_{3}}, \frac{3 u_{1}^{\prime}+2 u_{2}^{\prime}}{6 v_{1}+8 v_{2}+5 v_{3}}\right)
\end{aligned}
$$


Subject to:

$$
\begin{aligned}
& 4 u_{1}+3 u_{2}+2 u_{3}-7 v_{1}-7 v_{2}-7 v_{3} \leq 0 \\
& 7 u_{1}+5 u_{2}+u_{3}-5 v_{1}-9 v_{2}-7 v_{3} \leq 0 \\
& 7 u_{1}+u_{2}+7 u_{3}-4 v_{1}-6 v_{2}-5 v_{3} \leq 0 \\
& 2 u_{1}+u_{2}+3 u_{3}-5 v_{1}-9 v_{2}-8 v_{3} \leq 0 \\
& 6 u_{1}+2 u_{2}+4 u_{3}-6 v_{1}-8 v_{2}-5 v_{3} \leq 0 \\
& 4 u_{1}^{\prime}+3 u_{2}^{\prime}-7 v_{1}-7 v_{2}-7 v_{3} \leq 0 \\
& 7 u_{1}^{\prime}+5 u_{2}^{\prime}-5 v_{1}-9 v_{2}-7 v_{3} \leq 0 \\
& 5 u_{1}^{\prime}+u_{2}^{\prime}-4 v_{1}-6 v_{2}-5 v_{3} \leq 0 \\
& 6 u_{1}^{\prime}+u_{2}^{\prime}-5 v_{1}-9 v_{2}-8 v_{3} \leq 0 \\
& 3 u_{1}^{\prime}+2 u_{2}^{\prime}-6 v_{1}-8 v_{2}-5 v_{3} \leq 0 \\
& v_{1}+v_{2}+v_{3}+u_{1}+u_{2}+u_{3}+u_{1}^{\prime}+u_{2}^{\prime}=1 \\
& u_{1}, u_{2}, u_{3}, u_{1}^{\prime}, u_{2}^{\prime}, v_{1}, v_{2}, v_{3} \geq \varepsilon
\end{aligned}
$$

The maximum and minimum of numerator and denominator for each objective function at each level under the constraints are as follow:

$$
\begin{aligned}
& \bar{Y}_{1}^{(1)}=2.1, \underline{Y}_{1}^{(1)}=0.00009, \overline{\mathrm{Y}}_{2}^{(1)}=3.6, \underline{\mathrm{Y}}_{2}^{(1)}=0.00013, \overline{\mathrm{Y}}_{3}^{(1)}=3.231, \underline{\mathrm{Y}}_{3}^{(1)}=0.00015, \overline{\mathrm{Y}}_{4}^{(1)}= \\
& 1.385, \underline{Y}_{4}^{(1)}=0.00006, \underline{\mathrm{Y}}_{4}^{(1)}=2.769, \overline{\mathrm{Y}}_{5}^{(1)}=0.00012, \overline{\mathrm{Y}}_{1}^{(2)}=2.214, \underline{Y}_{1}^{(2)}=0.00007, \bar{Y}_{2}^{(2)}= \\
& 3.857, \underline{Y}_{2}^{(2)}=0.00012, \bar{Y}_{3}^{(2)}=2.727, \underline{Y}_{3}^{(2)}=0.00006, \bar{Y}_{4}^{(2)}=3.237, \underline{Y}_{4}^{(2)}=0.00007, \bar{Y}_{5}^{(2)}= \\
& 1.643, \underline{Y}_{5}^{(2)}=0.00005, \bar{X}_{1}^{(1)}=\bar{X}_{1}^{(2)}=7, \underline{X}_{1}^{(1)}=\underline{X}_{1}^{(2)}=1.374, \bar{X}_{2}^{(1)}=\bar{X}_{2}^{(2)}=9, \underline{X}_{2}^{(1)}=\underline{X}_{2}^{(2)}= \\
& 1.491, \bar{X}_{3}^{(1)}=\bar{X}_{3}^{(2)}=6, \underline{X}_{3}^{(1)}=\underline{X}_{3}^{(2)}=1.178, \bar{X}_{4}^{(1)}=\bar{X}_{4}^{(2)}=9, \underline{X}_{4}^{(1)}=\underline{X}_{4}^{(2)}=1.491, \bar{X}_{5}^{(1)}= \\
& \bar{X}_{5}^{(2)}=8, \underline{X}_{5}^{(1)}=\underline{X}_{5}^{(2)}=1.184 .
\end{aligned}
$$

Using above results, the FGP model (3) is formulated as follow: 


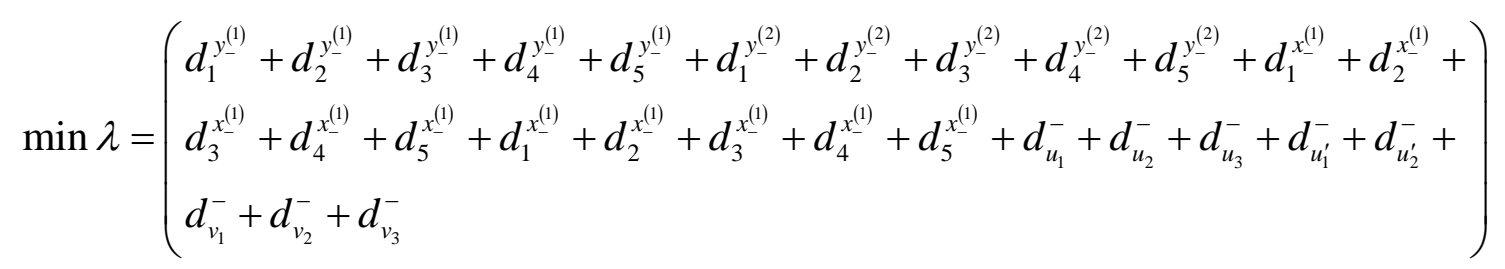

Subject to:

$$
\begin{aligned}
& -2.1+4 u_{1}+3 u_{2}+2 u_{3}+2.09991 d_{1}^{y_{1}^{(1)}} \geq 0 \\
& -3.6+7 u_{1}+5 u_{2}+u_{3}+3.59987 d_{2}^{y^{(1)}} \geq 0 \\
& -3.231+7 u_{1}+u_{2}+7 u_{3}+3.23085 d_{3}^{y_{-}^{(1)}} \geq 0 \\
& -1.385+2 u_{1}+u_{2}+3 u_{3}+1.38494 d_{4}^{y_{-}^{(1)}} \geq 0 \\
& -2.769+6 u_{1}+2 u_{2}+4 u_{3}+2.76888 d_{5}^{y^{(1)}} \geq 0 \\
& -2.214+4 u_{1}^{\prime}+3 u_{2}^{\prime}+2.21393 d_{1}^{y^{(2)}} \geq 0 \\
& -3.857+7 u_{1}^{\prime}+5 u_{2}^{\prime}+3.85688 d_{2}^{y_{2}^{(2)}} \geq 0 \\
& -2.727+5 u_{1}^{\prime}+u_{2}^{\prime}+2.72694 d_{3}^{y_{-}^{(2)}} \geq 0 \\
& -3.273+6 u_{1}^{\prime}+u_{2}^{\prime}+3.27293 d_{4}^{y_{-}^{(2)}} \geq 0 \\
& -1.643+3 u_{1}^{\prime}+2 u_{2}^{\prime}+1.64295 d_{5}^{y_{-}^{(2)}} \geq 0 \\
& 1.374-7 v_{1}-7 v_{2}-7 v_{3}+5.626 d_{1}^{x_{1}^{(1)}} \geq 0 \\
& 1.491-5 v_{1}-9 v_{2}-7 v_{3}+7.508 d_{2}^{x_{2}^{(1)}} \geq 0 \\
& 1.178-4 v_{1}-6 v_{2}-5 v_{3}+4.822 d_{3}^{x^{(1)}} \geq 0 \\
& 1.491-5 v_{1}-9 v_{2}-8 v_{3}+7.509 d_{4}^{x^{(1)}} \geq 0 \\
& 1.184-6 v_{1}-8 v_{2}-5 v_{3}+6.816 d_{5}^{x^{(1)}} \geq 0 \\
& 1.374-7 v_{1}-7 v_{2}-7 v_{3}+5.626 d_{1}^{x_{1}^{(2)}} \geq 0 \\
& 1.491-5 v_{1}-9 v_{2}-7 v_{3}+7.508 d_{2}^{x_{2}^{(2)}} \geq 0 \\
& 1.178-4 v_{1}-6 v_{2}-5 v_{3}+4.822 d_{3}^{x^{(2)}} \geq 0 \\
& 1.491-5 v_{1}-9 v_{2}-8 v_{3}+7.509 d_{4}^{x_{4}^{(2)}} \geq 0 \\
& 1.184-6 v_{1}-8 v_{2}-5 v_{3}+6.816 d_{5}^{x_{-}^{(2)}} \geq 0 \\
& -0.462+u_{1}+0.46199 d_{u_{1}}^{-} \geq 0
\end{aligned}
$$




$$
\begin{aligned}
& -0.643+u_{2}+0.64299 d_{u_{2}}^{-} \geq 0 \\
& -0.462+u_{3}+0.46199 d_{u_{3}}^{-} \geq 0 \\
& -0.545+u_{1}^{\prime}+0.35299 d_{u_{1}^{\prime}}^{-} \geq 0 \\
& -0.353+u_{2}^{\prime}+0.35299 d_{u_{2}^{\prime}}^{-} \geq 0 \\
& -1+v_{1}+0.99999 d_{v_{1}}^{-} \geq 0 \\
& -1+v_{2}+0.99999 d_{v_{2}}^{-} \geq 0 \\
& -0.237+v_{3}+0.23699 d_{v_{3}}^{-} \geq 0 \\
& u_{1}, u_{2}, u_{3}, u_{1}^{\prime}, u_{2}^{\prime}, v_{1}, v_{2}, v_{3}, d_{1}^{y_{-}^{(1)}}, d_{2}^{y_{-}^{(1)}}, d_{3}^{y_{-}^{(1)}}, d_{4}^{y_{-}^{(1)}}, d_{5}^{y_{-}^{(1)}}, d_{1}^{y_{-}^{(2)}}, d_{2}^{y_{-}^{(2)}}, d_{3}^{y_{-}^{(2)}}, d_{4}^{y_{-}^{(2)}}, d_{5}^{y_{-}^{(2)}}, d_{1}^{x_{-}^{(1)}}, \\
& d_{2}^{x_{-}^{(1)}}, d_{3}^{x_{-}^{(1)}}, d_{4}^{x_{-}^{(1)}}, d_{5}^{x_{-}^{(1)}}, d_{1}^{x_{-}^{(1)}}, d_{2}^{x_{-}^{(1)}}, d_{3}^{x_{-}^{(1)}}, d_{4}^{x_{-}^{(1)}}, d_{5}^{x_{-}^{(1)}}, d_{u_{1}^{-}}^{-}, d_{u_{2}^{-}}^{-}, d_{u_{3}}^{-}, d_{u_{1}^{-}}^{-}, d_{u_{-}^{-}}^{-}, d_{v_{1}}^{-}, d_{v_{-}}^{-}, d_{v_{3}}^{-} \geq 0
\end{aligned}
$$

Constraints (29)-(40)

The compromise weights obtained from our model for the above example is as follow:

$$
\begin{aligned}
& \lambda=11.063, u_{1}=0.202, u_{2}=0.168, u_{3}=0.00001, u_{1}^{\prime}=0.315, u_{2}^{\prime}=0.011, v_{1}=0.00001, v_{2}=0.067 \\
& v_{3}=0.237
\end{aligned}
$$

So, the profit efficiency and operational efficiency of each DMU can easily be calculated by using the Equation (1). Obtained results are reported in Table (2).

\section{- [Table 2 about here]}

According to the results of the Table (2), from the view point of the profitability assessment, we cannot find any full efficient branch. Similarly, all DMUs are not $100 \%$ efficient according to operational assessment. In fact, obtaining such results can be justified by this fact that all bank branches are evaluated from two different aspects, not only one, which gives a more realistic position of each branches.

\section{An application in banking efficiency}

Banking in Iran is one the most important industry that attracts very high lucrative jobs. Iranian banks tend to invest more in service and commercial sectors, due high profits in these sectors, rather than production. There are three commercial-public, five specialized-public, 20 private and two interest-free banks in Iran which manage over 12875 billion Rials in assets (each Dollar is about 35000 Rials). In addition, there are also five financial institutions and 
five foreign banks in Iran. The Iranian banks are regulated by central bank of the Islamic Republic of Iran. Totally, there are 40463 branches, 33517 automated teller machines $\left(\mathrm{ATM}_{\mathrm{s}}\right)$ and 3824850 point of sales (pos) in Iran. The case study of this paper is the branches of Maskan bank in West Azerbaijan province. Maskan bank is one of the public banks which established with the assets of over 200 million Rials in 1939 as a specialized bank in housing sector. This bank with the assets of 5848 billion Rials offers retail banking services, investment banking services and mortgages. The details of Maskan bank's tasks is as follow: housing and payment loans in building sector, house procurement, renovation of constructions and some roles according to the targets of Iran's central bank. Currently, Maskan bank includes over than 1240 branches across the country which act under supervision of provincial managements. The data of this study, see Table 3, are collected from 45 branches of Maskan bank in West Azerbaijan province. They were retrieved from each bank's audited financial reports over the year 2013.

\section{[Table 3 about here]}

Selecting inputs and outputs is the most important step in DEA to gain the suitable relative efficiency scores. To select relevant variables, this paper follows previous studies on assessing branches performance. Portela and Thanassoulis (2005) pointed out the changing role of banks from transaction-based to a sales-oriented role. Hence, they evaluated transaction efficiency, operational efficiency and profit efficiency of Portuguese bank branches by using DEA. They selected two inputs for operational efficiency included number of staff and rent, two inputs for profit efficiency included number of staff and supply costs and three inputs for transaction efficiency included

number ETMs (ATMs + CATs), rent and number of clients not registered. Also, they selected seven outputs for operational efficiency included number of clients, value of current accounts, value of other resources, value of titles deposited, value of credit by bank, value of credit by associates and number of transactions. For profit efficiency, they chosen four outputs included value of current accounts, value of other resources, value of credit over bank and value of credit associates. Finally, they considered three outputs for transaction efficiency included number of new registrations for internet use, number of transactions in CATs and number of deposits in ETMs. Oral and Yolalan (1990) evaluated operating and profit efficiency of 20 Turkish bank branches using a methodology based on DEA. They considered personal expenses, administrative expenses, depreciation, interest paid and sum of administrative expenses and depreciation as profit inputs. They also chosen number of personnel, number of terminals, number of 
commercial accounts, number of saving accounts, number of credit applications and sum of the commercial and saving accounts as the inputs for operational efficiency. In the outputs side, they considered interests earned, noninterest income and sum of the interest and non- interest income as the outputs of profit efficiency. In addition, time on general services, time on credits, time on deposits and time on foreign exchange are selected as the outputs of operating efficiency. Lin et al. (2008) evaluated the operating efficiency of 117 Taiwan bank branches by choosing following input: number of staff, interest expense, deposit operating amount and current deposit operating amounts. Also, they selected following outputs: loan operating amount, earning, operating revenue and interest revenue. Portela and Thanassoulis (2007) used number of staff and supply costs as inputs and value of current accounts, value of other resources, value of credit by bank and value of credit associates as outputs. Camanho and Dyson (1999) described an application of DEA to measure the profitability of Portuguese banks. The inputs are measured by number of employees in the branch, floor space of the branch (in $\mathrm{m}^{2}$ ), operational costs (costs of supplies and other services, in thousand escudos) and number of external ATMs. The outputs are measured by number of general service transactions performed by branch staff, number of transactions in external ATMs, number of all types of accounts at the branch, value of savings (in thousand escudos) and value of loans (in thousand escudos). Casu et al. (2004) estimated the productivity change of European banking between 1994 and 2000 by comparing parametric and non-parametric approach. They selected the average cost of labor (personnel expenses/total assets), deposits (interest expenses/customer and short-term funding) and capital (total capital expenses/total fixed assets) as input variables. The output variables included the traditional lending activity of banks (total loans) and the growing nonlending activities (securities). According to the availability of data and following previous studies, in this paper, four outputs for profit efficiency and three outputs for operational efficiency are selected. Also, three inputs are chosen and it is assumed that the inputs are common for both efficiencies. Tables (4) represents inputs and outputs for profit and operational efficiencies.

\section{[Table 4 about here]}

\section{Results and discussion}

This section reports the computational results and some observations and recommendation for policy makers. The empirical results are generated by a sample of 45 branches of a large public Iranian bank in West Azerbaijan province. The compromise weights for inputs and outputs are as follows: 
$u_{1}=0.00002, u_{2}=0.00001, u_{3}=0.00001, u_{4}=0.00001, u_{1}^{\prime}=0.00001, u_{2}^{\prime}=0.00001, u_{3}^{\prime}=0.92800$, $v_{1}=0.00001, v_{2}=0.00001, v_{3}=0.07200$

Now, profit and operational efficiencies for all branches are calculated using obtained compromise weights. Tables (5) and (6) represent the scores of profit and operational efficiencies under DEA-CCR and the proposed model, respectively.

[Table 5 and Table 6 about here]

As can be seen in Table (5), based on the results of classical DEA-CCR model, most DMUs has faily high profit and operation efficiencies. However, in compared to the classical DEA model, as shown in Table (6), DMUs do not high efficiencies when they are evaluated from two different hierarchical efficiencies simultaneously. More importantly, our proposed model can provide a better measure for DMUs and make a rational balance between profit and operational efficiencies by considering the higher importance of the profitability, which obviously, DMUs are not efficient as much as the traditional way. As expected, the overall results of both profit and operational efficiencies are appeared slightly lower than classic DEA, since it is more difficult for banks to be both profit and operational efficient at the same time. Hence, the combined values of the profit and operational efficiencies generated by our BLMO DEA model are less than the traditional DEA approach. Due to the generating the reasonable results, we can endorse on the proposed model validity which provides us to know the exact situation of branches. In the following, the results of the traditional DEA and our model are analyzed in details.

\subsection{Assessing profit efficiency of bank branches}

The profit efficiency analyzes shows the ability of a branch on converting expenses into revenues. It considers as an important assessor index for manager. So, assessing profit efficiency gives an ability to generate long-term and short-term profit. According to Table (5), branches 9, 17, 19, 23, 29 and 43 are fully profit efficient under DEACCR model. Table (6) shows that just two branches (branches 24 and 26) has efficiency scores 0.995 which is closed to one. Also, the branches which are fully efficient under normal DEA, considered as inefficient branches under proposed model. The mean of profit efficiency scores for all branches is 0.527 in the proposed model and 0.649 in the DEA-CCR model. It is clear that the results of the proposed model are compromise solution. In other 
words, in proposed model, branches want to maximize their profit efficiencies under a set of compromise weights for the indicators. The results of profit efficiencies for the DEA-CCR and proposed model are shown in Figure (1).

[Figure 1 about here]

\subsection{Assessing operational efficiency of bank branches}

Operational efficiency usually is measured by all types of operations that performed in a bank branch. Evaluating operation efficiency gives a reference for a bank's managers to defined operation strategies. Table (5) shows that the branches $3,6,11,14,19,21,25,27,31,36,41,43,45$ and 46 are fully operational efficient under DEA-CCR model. As shown in Table (6), some of mentioned branches have the least operational efficiency scores under proposed model. According to Table (6), under proposed model, branches 24, 26 and 35 have the efficiency scores close to one. Comparing operational efficiency scores between DEA-CCR model and proposed model reveals in Figure 2. It is clear that the operational efficiency scores generated by our model is less than the operational efficiency scores generated by DEA-CCR model in most cases.

--------- [Figure 2 about here] ----------

\subsection{Recommendations for policy remarks}

The idea of combination the DEA-CCR model and bi-level programming constructs an applicable decision making structure for managers to identify benchmark and problematic bank branches. According to the results obtained from our proposed model, here we will first depict the position of each branch and then suggest some practical points for the managers of those branches which have a low efficiency. In the following, Figure (3) shows the position of each branch based on the profit and operational efficiency assessment. We choose a threshold of $80 \%$ due to the managerial interests.

\section{[Figure 3 about here]}

According to the Figure (3), branches 4, 24, 26 and 35 are the most efficient ones which has the best performance from the view point of both profit and operational efficiency. The majority of the branches are relatively efficient but there is a need to take some critical strategies to detect their problems and to prevent from getting worse. For example, managers can change the number of staffs or transform inefficient personnel with efficient ones to improve their operational activities. Also, it is important to reduce costs and increase the number of $\mathrm{ATM}_{\mathrm{s}}$ in order to improve profitability of branches. 


\section{Conclusion and direction for future research}

This paper presented a bi-level multi-objective DEA (BLMO DEA) model to assess two different hierarchical dimensions of profit and operational efficiencies of a set of DMUs. Our proposed model is based on combination of the classical DEA model and bi-level programming problem. More precisely, in the proposed framework, two efficiencies were formulated as separate functions, but in the same model, in two different levels in which the first important efficiency was considered at the first level and the second important one was formulated at level 2. The model simultaneously maximized both efficiencies of all DMUs by considering the hierarchical relationship between them. The model has been validated using an illustrative example following by a real application in banking where it considered branches of one of the largest banks in Iran. The model calculated profit and operational efficiencies in which profit efficiency was considered at level 1 and operational efficiency was assigned to level 2. As the proposed BLMO DEA model had fractional objective functions, a fuzzy goal programming (FGP) methodology was applied for solving the proposed multi-level multi objective linear fractional programming model. The results showed that our model can provide a better and more comprehensive measure for efficiency of each bank branch. This measure is calculated a combined measure of efficiency which is obtained in two different levels, simultaneously, and hence it is expected to be less than the values of the single perspective evaluation. For future researches, it is worthwhile to develop a multi-level multi objective DEA model to consider more than two kinds of

efficiency measures. One can consider transactional, profit and operational efficiencies in three levels. Also, if the different efficiencies have the same priority, they can be considered in one level.

\section{References}

Ariff, M., Luc CAN, L. 2008. Cost and profit efficiency of Chinese banks: A non-parametric analysis. China Economic Review 19, 260-273.

Arjomandi, A., Valadkhani, A., O’Brien, M. 2014. Analysing banks' intermediation and operational performance using the Hicks-Moorsteen TFP index: The case of Iran. Research in International Business and Finance 30, $111-125$.

Camanho, A.S., Dyson, R.G., 1999. Efficiency, size, benchmarks and targets for bank branches: An application of data envelopment analysis. Journal of Operational Research Society 50, 903-915. 
Casu, B., Girardone, C., Molyneux, P. 2004. Productivity change in European banking: A comparison of parametric and non-parametric approaches. Journal of Banking \& Finance 28, 2521-2540.

Charnes, A., Cooper, W. W., Rhodes, E. 1978. Measuring the efficiency of decision making units. European Journal of Operational Research 2(6), 429-444.

Cook, W.D., Hababou, M. 2001. Sales performance measurement in bank branches. Omega 29, 299-307.

Duygun Fethi, M., Pasiouras, F. 2010. Assessing bank efficiency and performance with operational research and artificial intelligence techniques: A survey. European Journal of Operational Research 204,189-198.

Emrouznejad, A., M. Tavana, A. Hatami-Marbini (2014) "The State of the Art in Fuzzy Data Envelopment Analysis", in "Performance Measurement with Fuzzy Data Envelopment Analysis" published in Studies in Fuzziness and Soft Computing 309: 1:48, Springer-Verlag.

Emrouznejad, A., \& Yang, G. L. (2018). A survey and analysis of the first 40 years of scholarly literature in DEA: 1978-2016. Socio-Economic Planning Sciences, 61, 4-8.

Ghasemi M.R., J. Ignatius, A. Emrouznejad (2014) A bi-objective weighted model for improving the discrimination power in MCDEA, European Journal of Operational Research, 233 (3): 640-650

Giokas, D.I. 2008. Assessing the efficiency in operations of a large Greek bank branch network adopting different economic behaviors. Economic Modelling 25, 559-574.

Jahanshahloo, G.R., Amirteimoori, A.R., Kordrostami, S. 2004. Multi-component performance, progress and regress measurement and shared inputs and outputs in DEA for panel data: an application in commercial bank branches. Applied Mathematics and Computation 151, 1-16.

Lachhwani, K. 2015. Modified FGP approach for multi-level multi objective linear fractional programming problem. Applied Mathematics and Computation 266, 1038-1049.

Lin, T.T., Lee, C-C., Chiu, T-F. 2009. Application of DEA in analyzing a bank's operating performance. Expert Systems with Applications 36, 8883-8891.

Manandhar, R., Tang, J.C.S. 2002. The evaluation of bank branch performance using data envelopment analysis: A framework. Journal of High Technology Management Research 13, 1-17.

Oral, M., Kettani, O., Yolalan, R. 1992. An empirical study on analyzing the productivity of bank branches. IIE Transactions, 24(5), 166-176. 
Oral, M., Yolalan, R. 1990. An empirical study on measuring operating efficiency and profitability of bank branches. European Journal of Operational Research 45, 282-294.

Paradi, J.C., Rouatt, S., Zhu, H. 2011. Two-stage evaluation of bank branch efficiency using data envelopment analysis. Omega 39, 99-109.

Paradi, J.C., Zhu, H. 2012. A survey on bank branch efficiency and performance research with data envelopment analysis. Omega 41, 61-79.

Parkan, C. 1987. Measuring the efficiency of service operations: an application to bank branches. Engineering costs and production Economics, 12, 237-242.

Portela, M.C.A.S., Thanassoulis, E. 2005. Profitability of a sample of Portuguese bank branches and its decomposition into technical and allocative components. European Journal of Operational Research 162, $850-866$.

Portela, M.C.A.S., Thanassoulis, E. 2007. Comparative efficiency analysis of Portuguese bank branches. European Journal of Operational Research 177, 1275-1288.

Ray, S., 2016. Cost efficiency in an Indian bank branch network: A centralized resource allocation model. Omega $65,69-81$.

Sherman, H.D., Gold, F. 1985. Bank branch operating efficiency: evaluation with data envelopment analysis. Journal of Banking and Finance 9, 297-315.

Wanke P., C. Barros and A Emrouznejad (2017) A Comparison between Stochastic DEA and Fuzzy DEA approaches: Revisiting Efficiency in Angolan Banks, RAIRO-Operations Research, Forthcoming.

Yang, Z. 2009. Bank Branch Operating Efficiency: A DEA Approach. Proceedings of the International Multi Conference of Engineers and Computer Scientists 2009 Vol II IMECS 2009, March 18 - 20, Hong Kong. 


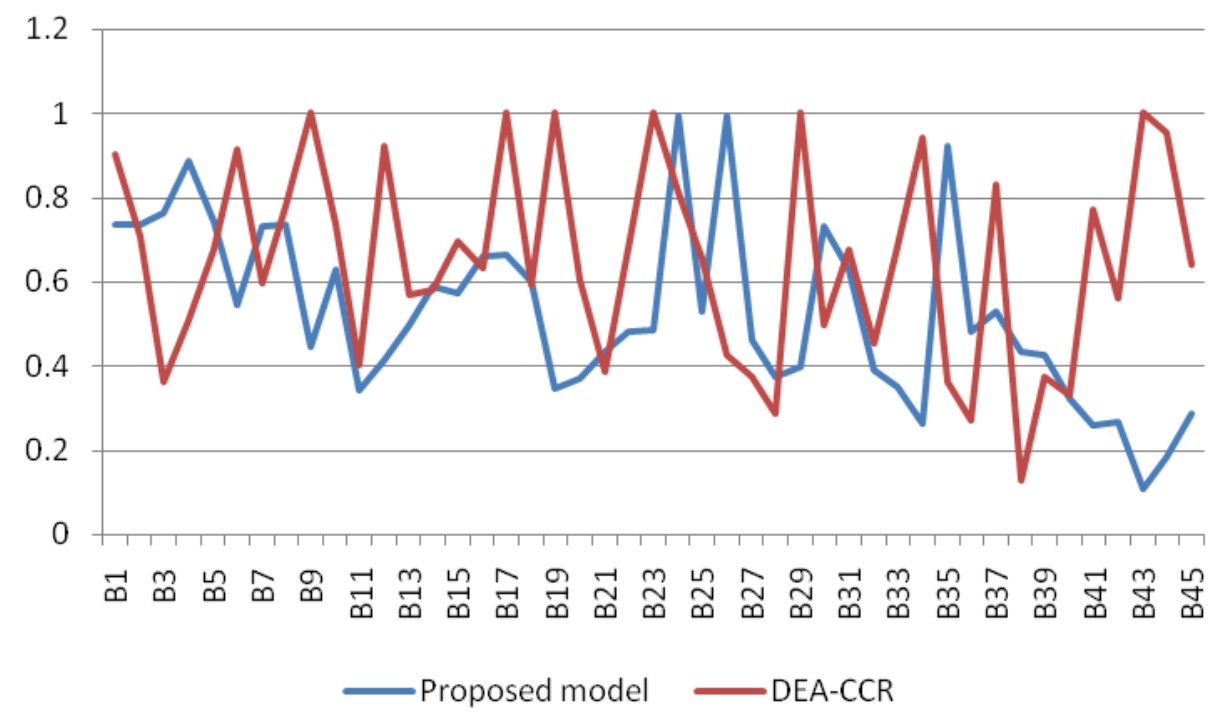

Figure 1: Profit efficiency scores for bank branches based on DEA-CCR and proposed models 


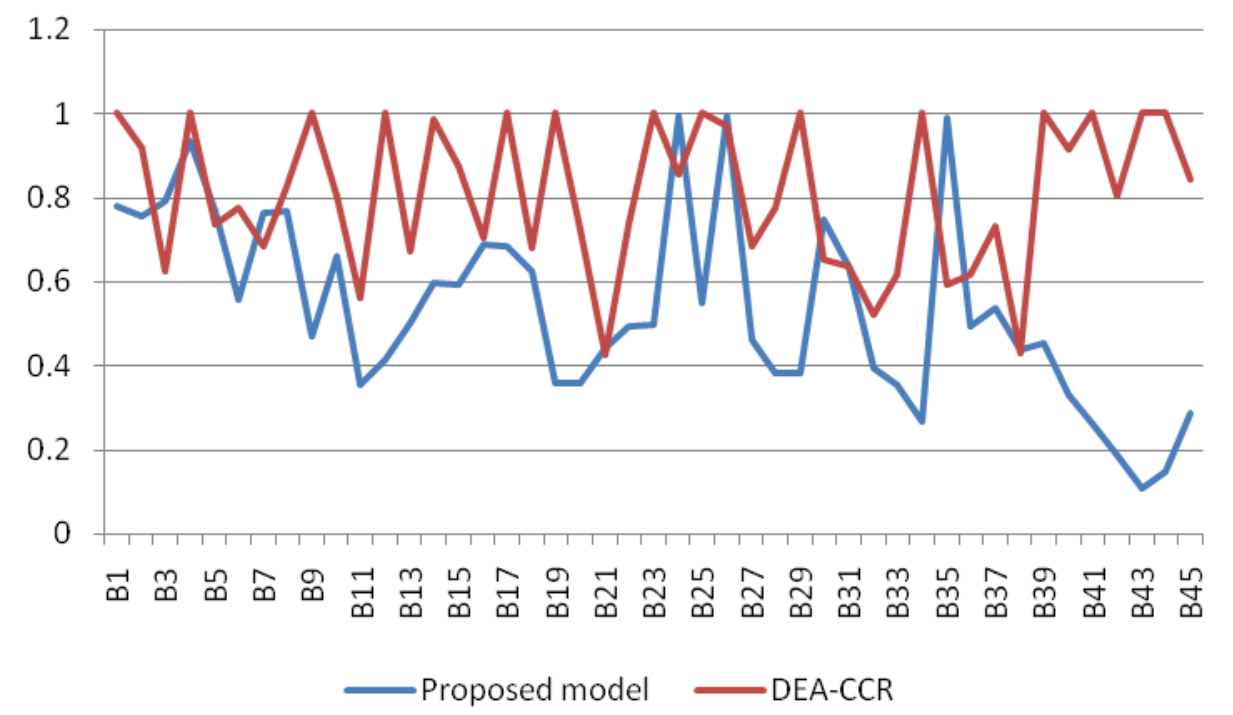

Figure 2: Operational efficiency scores for bank branches based on DEA-CCR and proposed models 


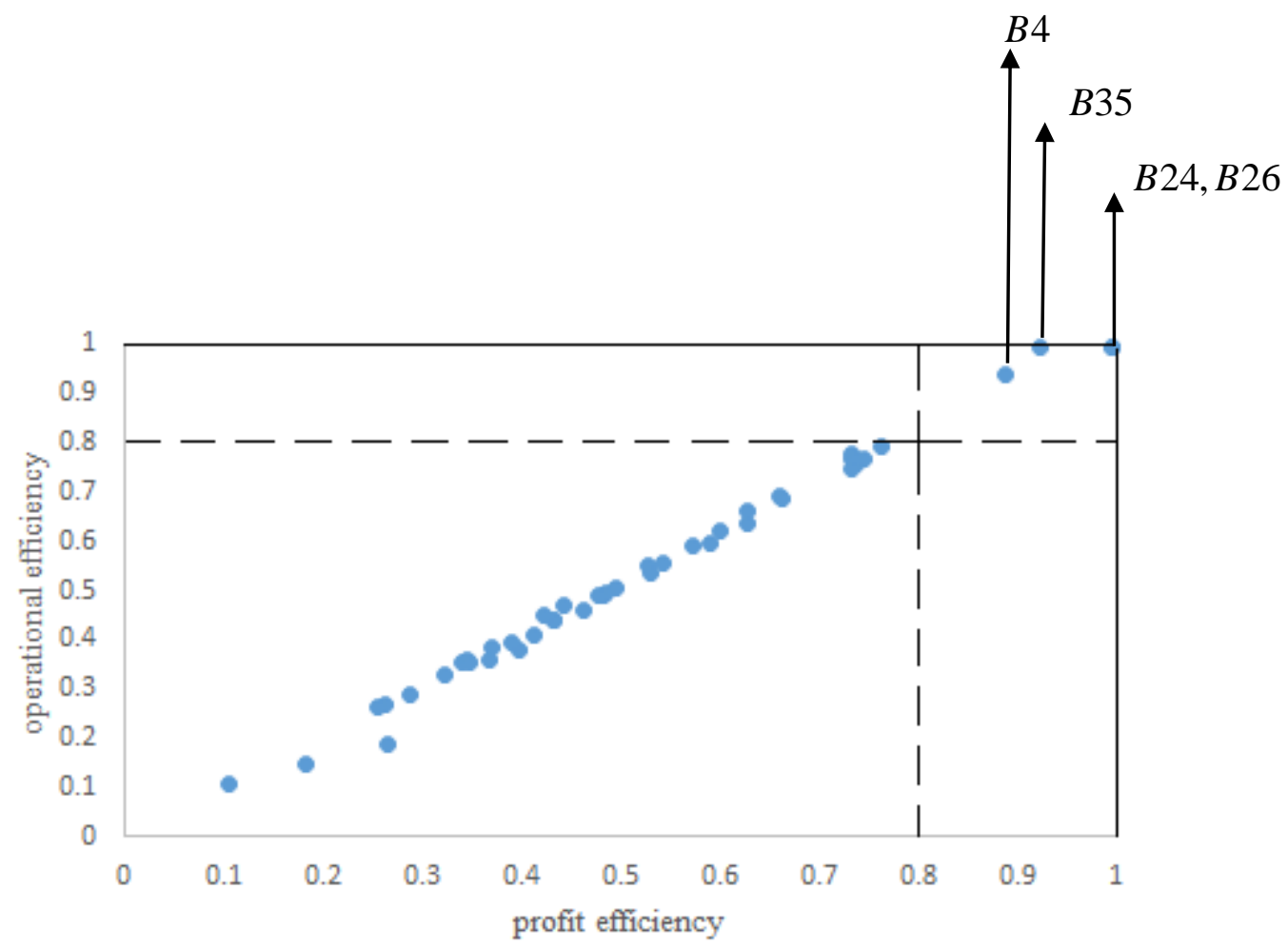

Figure3: Profit and operational efficiency scores based on the proposed model 
Table 1: The amounts of input and output for the numerical example

\begin{tabular}{lllllllll}
\hline DMU & $x_{1}$ & $x_{2}$ & $x_{3}$ & $Y_{1}^{\prime}$ & $Y_{2}^{\prime}$ & $Y_{1}$ & $Y_{2}$ & $Y_{3}$ \\
\hline DMU1 & 7 & 7 & 7 & 4 & 3 & 4 & 3 & 2 \\
\hline DMU2 & 5 & 9 & 7 & 7 & 5 & 7 & 5 & 1 \\
\hline DMU3 & 4 & 6 & 5 & 5 & 1 & 7 & 1 & 7 \\
\hline DMU4 & 5 & 9 & 8 & 6 & 1 & 2 & 1 & 3 \\
\hline DMU5 & 6 & 8 & 5 & 3 & 2 & 6 & 2 & 4 \\
\hline
\end{tabular}


Table 2: Efficiency scores for each DMU using proposed model

\begin{tabular}{ccc}
\hline DMU & profit efficiency & operational efficiency \\
\hline DMU1 & 0.617 & 0.608 \\
\hline DMU2 & 0.996 & 0.999 \\
\hline DMU3 & 0.997 & 0.999 \\
\hline DMU4 & 0.229 & 0.761 \\
\hline DMU5 & 0.899 & 0.562 \\
\hline
\end{tabular}


Table 3: The data for 45 branches of Maskan bank in Iran

\begin{tabular}{|c|c|c|c|c|c|c|c|c|}
\hline Branches & $X_{1}$ & $X_{2}$ & $\begin{array}{c}X_{3} \\
\text { (1 million) }\end{array}$ & $\begin{array}{c}Y_{1}, \mathrm{Y}_{1}^{\prime} \\
\text { (1 million) }\end{array}$ & $\begin{array}{c}Y_{2}, Y_{2}^{\prime} \\
\text { (1 million) }\end{array}$ & $\begin{array}{c}Y_{3} \\
\text { (1 million) }\end{array}$ & $Y_{3}^{\prime}$ & $\begin{array}{c}Y_{4} \\
\text { (1 million) }\end{array}$ \\
\hline branch1 & 12 & 26 & 804 & 456,954 & $3,078,223$ & 216,348 & 8641 & 224,346 \\
\hline branch2 & 2 & 13 & 456 & 265,054 & $1,686,128$ & 164,047 & 8642 & 147,367 \\
\hline branch3 & 2 & 16 & 445 & 368,740 & $1,602,520$ & 133,146 & 8643 & 121,380 \\
\hline branch4 & 4 & 15 & 365 & 357,220 & $1,550,541$ & 130,834 & 8644 & 82,158 \\
\hline branch5 & 3 & 9 & 251 & 237,843 & 829,360 & 81,017 & 8645 & 55,184 \\
\hline branch6 & 3 & 8 & 218 & 160,461 & 510,891 & 47,368 & 8646 & 37,974 \\
\hline branch7 & 1 & 7 & 303 & 170,451 & $1,138,122$ & 112,381 & 8647 & 72,367 \\
\hline branch8 & 1 & 4 & 141 & 68,586 & 547,882 & 55,433 & 8648 & 36,483 \\
\hline branch9 & 1 & 8 & 322 & 103,614 & 754,295 & 64,872 & 8649 & 44,725 \\
\hline branch10 & 1 & 6 & 160 & 81,578 & 512,820 & 49,266 & 8650 & 31,590 \\
\hline branch11 & 1 & 6 & 171 & 67,167 & 269,997 & 27,855 & 8651 & 14,785 \\
\hline branch12 & 1 & 7 & 178 & 128,590 & 269,562 & 32,951 & 8652 & 20,481 \\
\hline branch13 & 1 & 4 & 159 & 141,437 & 292,296 & 23,341 & 8653 & 24,470 \\
\hline branch14 & 1 & 3 & 125 & 62,332 & 357,025 & 36,982 & 8654 & 36,889 \\
\hline branch15 & 1 & 6 & 152 & 110,453 & 389,366 & 36,590 & 8655 & 24,418 \\
\hline branch16 & 1 & 5 & 166 & 105,461 & 538,280 & 49,491 & 8656 & 34,892 \\
\hline branch17 & 1 & 15 & 522 & 345,589 & $1,655,209$ & 142,575 & 8657 & 141,292 \\
\hline branch18 & 1 & 4 & 144 & 86,962 & 416,081 & 42,483 & 8658 & 25,040 \\
\hline branch19 & 1 & 4 & 136 & 49,416 & 222,485 & 19,809 & 8659 & 17,191 \\
\hline branch20 & 1 & 4 & 153 & 70,539 & 232,802 & 30,918 & 8660 & 30,092 \\
\hline branch21 & 1 & 4 & 139 & 103,788 & 229,915 & 25,978 & 8661 & 11,158 \\
\hline branch22 & 2 & 4 & 170 & 99,221 & 366,976 & 33,261 & 8662 & 33,939 \\
\hline branch23 & 1 & 4 & 149 & 134,188 & 268,220 & 14,982 & 8663 & 23,760 \\
\hline branch24 & 1 & 5 & 143 & 313,865 & 445,250 & 34,588 & 8664 & 42,146 \\
\hline branch 25 & 1 & 4 & 116 & 55,681 & 302,828 & 31,302 & 8665 & 17,699 \\
\hline branch26 & 1 & 6 & 175 & 209,133 & 759,668 & 78,004 & 8666 & 84,576 \\
\hline branch27 & 2 & 4 & 144 & 118,813 & 240,913 & 24,185 & 8667 & 23,513 \\
\hline branch28 & 1 & 4 & 114 & 61,809 & 178,185 & 14,536 & 8668 & 13,273 \\
\hline branch29 & 1 & 4 & 164 & 131,382 & 205,402 & 27,575 & 8669 & 28,079 \\
\hline branch30 & 1 & 4 & 129 & 115,023 & 422,080 & 39,699 & 8670 & 37,351 \\
\hline branch31 & 1 & 5 & 109 & 110,002 & 271,619 & 26,725 & 8671 & 19,574 \\
\hline branch32 & 1 & 5 & 131 & 122,927 & 152,534 & 12,417 & 8672 & 8,413 \\
\hline branch33 & 1 & 4 & 119 & 46,046 & 186,807 & 19,756 & 8673 & 17,659 \\
\hline branch34 & 1 & 4 & 114 & 55,303 & 108,822 & 10,999 & 8674 & 6,199 \\
\hline branch35 & 1 & 5 & 108 & 27,925 & 587,935 & 61,172 & 8675 & 23,642 \\
\hline branch36 & 2 & 5 & 123 & 76,967 & 256,836 & 22,433 & 8676 & 20,930 \\
\hline branch37 & 1 & 3 & 111 & 60,190 & 274,111 & 27,999 & 8677 & 26,426 \\
\hline branch38 & 2 & 3 & 87 & 57,095 & 154,111 & 15,607 & 8678 & 11,546 \\
\hline branch39 & 1 & 3 & 115 & 19,950 & 277,682 & 31,041 & 8679 & 9,992 \\
\hline branch40 & 1 & 4 & 113 & 51,522 & 152,713 & 17,461 & 8680 & 8,760 \\
\hline branch41 & 1 & 3 & 90 & 29,963 & 100,406 & 10,214 & 8681 & 6,999 \\
\hline branch42 & 1 & 3 & 102 & 63,957 & 34,493 & 35,359 & 8682 & 23,790 \\
\hline branch43 & 1 & 4 & 132 & 28,554 & 47,715 & 4,350 & 8683 & 3,570 \\
\hline branch44 & 1 & 4 & 105 & 63,604 & 12,728 & 13,820 & 8684 & 9,908 \\
\hline branch45 & 1 & 3 & 90 & 57,308 & 80,898 & 7,863 & 8685 & 5,520 \\
\hline
\end{tabular}


Table 4: Inputs and outputs set

\begin{tabular}{cc}
\hline Inputs & Outputs \\
\hline$X_{1}=$ Number of ATM & Profit efficiency \\
$X_{2}=$ Number of staff & $Y_{1}=$ Value of deposits \\
$X_{3}=$ Total costs & $Y_{2}=$ Value of loans \\
& $Y_{3}=$ Total Profit \\
& $Y_{4}=$ Total revenue \\
& Operational efficiency \\
& $Y_{1}^{\prime}=$ Value of deposits \\
& $Y_{2}^{\prime}=$ Value of loans \\
\end{tabular}


Table 5: The profit and operational efficiency scores generated by DEA-CCR model

\begin{tabular}{cccccc}
\hline bank branches & profit efficiency & operational efficiency & $\begin{array}{c}\text { bank } \\
\text { branches }\end{array}$ & profit efficiency & $\begin{array}{c}\text { operational } \\
\text { efficiency }\end{array}$ \\
\hline branch 1 & 0.901 & 1.000 & branch 24 & 0.808 & 0.852 \\
\hline branch 2 & 0.705 & 0.916 & branch 25 & 0.653 & 1.000 \\
\hline branch 3 & 0.362 & 0.622 & branch 26 & 0.426 & 0.968 \\
\hline branch 4 & 0.508 & 1.000 & branch 27 & 0.374 & 0.682 \\
\hline branch 5 & 0.674 & 0.734 & branch 28 & 0.285 & 0.773 \\
\hline branch 6 & 0.913 & 0.775 & branch 29 & 1.000 & 1.000 \\
\hline branch 7 & 0.595 & 0.682 & branch 30 & 0.494 & 0.652 \\
\hline branch 8 & 0.778 & 0.826 & branch 31 & 0.674 & 0.637 \\
\hline branch 9 & 1.000 & 1.000 & branch 32 & 0.454 & 0.522 \\
\hline branch 10 & 0.733 & 0.803 & branch 33 & 0.681 & 0.615 \\
\hline branch 11 & 0.401 & 0.561 & branch 34 & 0.942 & 1.000 \\
\hline branch 12 & 0.921 & 1.000 & branch 35 & 0.361 & 0.591 \\
\hline branch 13 & 0.566 & 0.671 & branch 36 & 0.270 & 0.615 \\
\hline branch 14 & 0.581 & 0.986 & branch 37 & 0.830 & 0.732 \\
\hline branch 15 & 0.695 & 0.874 & branch 38 & 0.127 & 0.430 \\
\hline branch 16 & 0.633 & 0.704 & branch 39 & 0.372 & 1.000 \\
\hline branch 17 & 1.000 & 1.000 & branch 40 & 0.328 & 0.911 \\
\hline branch 18 & 0.591 & 0.680 & branch 41 & 0.772 & 1.000 \\
\hline branch 19 & 1.000 & 1.000 & branch 42 & 0.560 & 0.803 \\
\hline branch 20 & 0.602 & 0.724 & branch 43 & 1.000 & 1.000 \\
\hline branch 21 & 0.385 & 0.426 & branch 44 & 0.951 & 0.842 \\
\hline branch 22 & 0.678 & 0.735 & branch 45 & 0.637 & \\
\hline branch 23 & 1.000 & 1.000 & & & \\
\hline
\end{tabular}


Table 6: The profit and operational efficiency scores generated by the proposed model

\begin{tabular}{cccccc}
\hline bank branches & profit efficiency & operational efficiency & $\begin{array}{c}\text { bank } \\
\text { branches }\end{array}$ & profit efficiency & $\begin{array}{c}\text { operational } \\
\text { efficiency }\end{array}$ \\
\hline branch 1 & 0.734 & 0.778 & branch 24 & 0.995 & 0.995 \\
\hline branch 2 & 0.737 & 0.758 & branch 25 & 0.527 & 0.550 \\
\hline branch 3 & 0.764 & 0.793 & branch 26 & 0.995 & 0.995 \\
\hline branch 4 & 0.889 & 0.937 & branch 27 & 0.462 & 0.461 \\
\hline branch 5 & 0.745 & 0.768 & branch 28 & 0.371 & 0.383 \\
\hline branch 6 & 0.543 & 0.557 & branch 29 & 0.398 & 0.382 \\
\hline branch 7 & 0.732 & 0.765 & branch 30 & 0.733 & 0.748 \\
\hline branch 8 & 0.735 & 0.768 & branch 31 & 0.627 & 0.638 \\
\hline branch 9 & 0.444 & 0.471 & branch 32 & 0.391 & 0.395 \\
\hline branch 10 & 0.628 & 0.659 & branch 33 & 0.349 & 0.352 \\
\hline branch 11 & 0.341 & 0.354 & branch 34 & 0.262 & 0.267 \\
\hline branch 12 & 0.413 & 0.412 & branch 35 & 0.922 & 0.992 \\
\hline branch 13 & 0.495 & 0.503 & branch 36 & 0.479 & 0.492 \\
\hline branch 14 & 0.590 & 0.596 & branch 37 & 0.530 & 0.537 \\
\hline branch 15 & 0.572 & 0.592 & branch 38 & 0.432 & 0.439 \\
\hline branch 16 & 0.661 & 0.690 & branch 39 & 0.423 & 0.452 \\
\hline branch 17 & 0.663 & 0.685 & branch 40 & 0.322 & 0.329 \\
\hline branch 18 & 0.600 & 0.623 & branch 41 & 0.256 & 0.262 \\
\hline branch 19 & 0.346 & 0.358 & branch 42 & 0.266 & 0.189 \\
\hline branch 20 & 0.369 & 0.358 & branch 43 & 0.106 & 0.107 \\
\hline branch 21 & 0.432 & 0.441 & branch 44 & 0.183 & 0.148 \\
\hline branch 22 & 0.483 & 0.492 & branch 45 & 0.287 & \\
\hline branch 23 & 0.485 & 0.496 & & & \\
\hline
\end{tabular}

